\title{
Amperometric Determination of Acetaminophen (paracetamol) Using Graphene Oxide Modified Glassy Carbon Electrode
}

\author{
Periyalagan Alagarsamy ${ }^{1}$, Ramki Settu ${ }^{2}$, Shen-Ming Chen ${ }^{2, *}$, Tse-Wei Chen ${ }^{2}$, In-Seok Hong ${ }^{1}$, \\ Mettu Mallikarjuna Rao ${ }^{1}$ \\ ${ }^{1}$ Department of Chemistry, College of Natural Science, Kongju National University, Republic of \\ Korea. \\ ${ }^{2}$ Electroanalysis and Bioelectrochemistry Lab, Department of Chemical Engineering and \\ Biotechnology, National Taipei University of Technology, No.1, Section 3, Chung-Hsiao East Road, \\ Taipei 106, Taiwan (R.O.C). \\ *E-mail: smchen78@ms15.hinet.net
}

doi: $10.20964 / 2018.08 .01$

Received: 16 March 2018 / Accepted: 12 May 2018 / Published: 5 July 2018

In this work, a simple, disposable electrochemical sensor based on graphene oxide (GO) modified glassy carbon electrode (GCE) was reported, which was used for the determination of pain reliever acetaminophen (AC). Scanning electron microscopy (SEM), Fourier transform infrared spectroscopy (FT-IR), Raman spectroscopy were utilized to characterize the graphene oxide. In addition, the GO/GCE displayed excellent electrocatalytic activity towards the electrochemical determination of AC. Under the optimized conditions, the sensing platform showed wide linear responses for AC from 0.1 to $430 \mu \mathrm{M}$ with detection limits $(\mathrm{S} / \mathrm{N}=3)$ of $21 \mathrm{nM}$. The proposed sensor displayed good selectivity, sensitivity, and stability. Furthermore, GO modified electrode was also applied to detect practical samples with satisfactory results.

Keywords: painkiller, acetaminophen, graphene oxide, modified electrode, electrochemical sensor,

\section{FULL TEXT}

(C) 2018 The Authors. Published by ESG (www.electrochemsci.org). This article is an open access article distributed under the terms and conditions of the Creative Commons Attribution license (http://creativecommons.org/licenses/by/4.0/). 